\title{
Chapter 22 E-Planning Applications in Turkish Local Governments
}

\author{
Koray Velibeyoglu \\ Izmir Institute of Technology, Turkey
}

\begin{abstract}
This chapter examines the pivotal relationship between e-planning applications and their organizational context. It employs various evaluation frameworks by searching explicit and implicit structures behind the implementation process. The study is largely based on the statement that 'the organizational and user dimension of implementation factors more than technical ones, constitute the main obstacles to the improvement of e-planning tools in urban planning agencies'. The empirical part of the study scrutinizes the personal and situational factors of users in the process of implementation, benefits and constraints of an e-planning implementation and planning practitioners' perception of new technologies on urban planning practice and debate. Using a case study research in Turkish local governments, the findings of this study reveal that the organizational and human aspects of high order information systems are still the biggest obstacle in the implementation process.
\end{abstract}

\section{INTRODUCTION}

An increasingly developmental role beyond the traditional role of service provision pushes city governments to be more proactive and inventive in the application of information and communication technologies (ICTs). For the purposes of city governments the role of ICTs encompasses a number of fields and actions like catalyzing economic de-

DOI: 10.4018/978-1-61520-929-3.ch022 velopment, inhibiting social inequality, controlling and managing urban development and supporting accessibility to local information and services. In urban development, ICTs contribute to management and monitoring of urban development through various e-applications and spatial information systems like geographical information systems (GIS). ICTs contribution to urban development, however, is closely aligned with the soft organizational realities (e.g., cultural, structural, political, personal factors) that are highly influential in the implementation 
of ICT-based systems and policies. Therefore, in order to understand the impacts of ICTs in organizations one should carefully look into the computer-aided work practice and everyday use of sound technological systems.

The chapter heavily draws on a comprehensive field study conducted in a sample of local government urban planning agencies of Turkey. The major question that lies behind this study is how organizational and human aspects of technological applications affect success and failure of e-planning. The study, then, addresses the soft organizational realities of e-planning applications.

The term e-planning applications used in this chapter refer to the use of ICTs and information systems to advance urban planning and management. Technological applications on which e-planning are based could be grouped into three categories (Budthimedhee et al., 2002). The first group of technologies refers to technologies about data management and distribution. The second is related with mapping and processing of spatial data that is vital for urban planning and management. The last group is composed of interface technologies, which are concerned with creating more effective information environments via representation and modeling.

The basis of the study is largely determined by the human factor. Therefore, e-planning applications of selected planning agencies is measured by using qualitative methods (through surveys and interviews), and the supporting documents based on respondents' perceptions. The user surveys sketch the profile of a planning practitioner in three ways: (1) personal and technological background (e.g. age, sex, education, computer literacy, job title, duration of work), (2) technical knowledge on e-planning applications (3) attitude toward new technologies and their future role in planning practice and debate. Interviews also provide background information on the obstacles and benefits derived from e-planning applications in case study organizations.
This study has three parts. Firstly, as a background, the chapter includes a historical overview of ICTs and e-planning in Turkish case. Then, soft organizational realities of e-planning are exemplified in the selected Turkish local governments. An empirical study reveals the current state of e-planning applications in respondent local governments. It also scrutinizes planning practitioner's commitment and dependence on e-planning applications in practice. The chapter concludes with lessons learnt from e-planning in the case study organizations and with a prospective research agenda on the organizational dimension of ICTs for urban planning agencies.

\section{BACKGROUND}

\section{Development of Urban Technologies in Turkish Local Governments}

According to data provided from the 2000 General Population Census, $32 \%$ of the population live in 16 cities with metropolitan municipality organizations, and 22 million people live in municipal jurisdictions which comprise $41 \%$ of Turkey's population (DIE, 2000). The model of metropolitan municipality has been redesigned in recent years and the new municipal legislation (Law 5216), enforced the use of spatial information systems (e.g., GIS) for inter-municipal activities. Although such legal provisions about GIS can be considered a positive reform, they created new implementation problems for the metropolitan municipalities. As growing IS literature indicates, setting up and running a high order information system is not just a mere technical process but a process that, to a large extent, is affected by many complex factors such as human resources, organizational and socio-political structure (Cavric, 2002; Klosterman, 2001; Vonk 2003).

Municipalities in Turkey are responsible for delivering basic urban services (e.g., infrastruc- 
ture development, fire department operations, garbage collection, planning services etc.) to the public that require collecting accurate information about their environment and efficient use of these data to perform their tasks. Municipalities collect and manage both spatial data (e.g., master plan and application plans, land-use maps, cadastre maps) and non-spatial data (e.g., water system revenues, environmental taxation, and building permits) in their operations. Almost $80 \%$ of total data exploited by municipalities is spatial data. Municipalities are increasingly using GIS, spatial decision support systems (SDSS), management information systems (MIS), and the Internet to carry out administrative, auditing, and planning tasks more efficiently. Among these technologies, GIS is the key for municipal operations with its enormous strength to process spatial data.

Plan making, programming and decisionmaking are largely dependent on the collection, storing, preservation and management of spatial information and information related to urban land use. Therefore, public works and urban planning are the major issues of Municipal GIS operations. In the Turkish case, Eskisehir, Istanbul, and Bursa are the leading cities, in which implementation process of GIS projects is still in progress (Velibeyoglu \& Yigitcanlar, 2008). Since municipalities are the primary customers for the GIS market in Turkey the term urban information system (UIS) has become more popular in recent years (Velibeyoglu, 2005). By combining many of the municipal services into UIS, it is aimed that many municipal services will be integrated with local e-government applications. Thus the system will be shared with other local governments and central public organizations in the city, and thus service integration will be obtained.

This trend encompasses a strategy that aims to increase sharing of information both within and among institutions (Cavric, 2002). However, compared to the types of departmental and individual system implementation, this approach needs accumulation of knowledge, which means local governments should cope with more problems within the current organizational structure. Problems in running and using UIS in Turkish metropolitan municipalities can be summarized in three major points:

Software: When we look into the current state of municipal e-planning applications, it is seen that technology investments are primarily focused on CAD-based systems. The rationale behind this tendency is the complexity of the GIS packages and their requirements for having a good command of a foreign language and advanced knowledge of programming and computer literacy. For this reason, many municipalities turned to CAD-based applications instead of costly GIS investments.

Staffing and Management Structures: There are major bottlenecks in recruiting trained staff in terms of obtaining and processing spatial data. This is largely because of the problem of public sector employment policy that neither computer skills nor individual productivity is encouraged and rewarded by the administrative system.

Data Issues: Digitalization of spatial data is in its initial stages, and lacks quality and quantity. For this reason, the concept of UIS in Turkey is frequently considered for digital map production. In terms of data sharing, municipal organizations cannot competently interact with the public and other public initiatives on-line. In recent years, however, some promising implementations have been done. Telecommunications infrastructure of Izmir Metropolitan Municipality called "IzmirNET" has provided data exchange between district municipalities and public institutions in the city of Izmir (Velibeyoglu \& Yigitcanlar, 2008).

\section{History of E-Planning in Turkey}

Turkey was first confronted with computer systems in the early 1960s. In the same period, started state planning and, within this process, the concept of urban planning gained prevalence. After the 1960s, land use models and transportation models applied contemporary planning techniques, in 
'Metropolitan Planning Offices' set up in Istanbul, Ankara and Izmir. But considering the fact that mainframe computers were less in number and costly in prices and run only by computer experts, it can be said that scientific methods for urban planning and systems approach could not find true place in the practice of Turkish urban planning in this decade, a period in which the impacts of rapid urbanization were more severe (Velibeyoglu, 2004).

The 1980s witnessed technological transformation as much as it did economic and political changes. Parallel to the liberal economic policies implemented, there was a rapid development in the telecommunications sector and microcomputers (PCs) entered the Turkish market very quickly (Wolcott \& Cagiltay, 2001). Local governments began to gain financial and administrative autonomy, and the reconstruction plans delegated to them after 1985 (with the Reconstruction Law 3194) pave the way to important developments in the professional practice. In the same period, metropolitan municipalities were established by Law 3030. The first applications in the area of information systems in planning were carried out by metropolitan municipalities. During this period, the Istanbul Metropolitan Municipality opened tender for the production of digital maps covering its jurisdictions. Since then, many local governments adopted institutional GIS systems (Velibeyoglu, 2004).

In recent years, spatial information systems in urban planning, especially GIS, have been mentioned frequently but they have not been fully adopted yet. In the metropolitan municipalities of big Turkish cities such as Istanbul, Ankara, Izmir and Bursa, and in some metropolitan district municipalities (e.g., Kadıköy-Istanbul, NilüferBursa), GIS has been in use. Despite a number of opportunities such as design, visualization, participation, decision making and modeling provided by information technologies and systems, very few of them have been used in planning agencies. As the early adopters of these systems local government institutions in Turkey have gained important achievements in the automation of basic urban services. However, no innovative use of various e-planning applications such as remote sensing, spatial modeling, simulation and forecasting, for example, in the institutional practice of urban planning and management has been observed so far (Velibeyoglu \& Saygin, 2005). Beginning in the pre-implementation stage there are serious obstacles in this process. The following section examines the problems and the opportunities faced by planning organizations.

\section{E-Planning in Practice: The Case of Turkish Metropolitan Planning Agencies}

The empirical research was based on the assumption that organizational and user dimensions, more than technical factors, constitute the main obstacles faced by urban planning agencies in the utilization of e-planning applications (Velibeyoglu, 2004). The implementation environment incorporates not just technological but also social and organizational factors. The role of user values and organizational environment is even more important in developing countries. In order to test this argument, planning departments of three Turkish metropolitan municipalities (Ankara, Izmir, and Bursa) were selected as a major unit of analysis according to criteria below:

- $\quad$ awareness and operation of various e-planning applications;

- $\quad$ existence of a planning department as a single, defined unit within the organization;

- $\quad$ easy access to richer financial resources and larger size of planning staff;

- availability of different planning issues in different operational levels that creates further opportunities to observe intra/inter organizational context. 
Figure 1. The variables and their relationships with the objectives of the survey

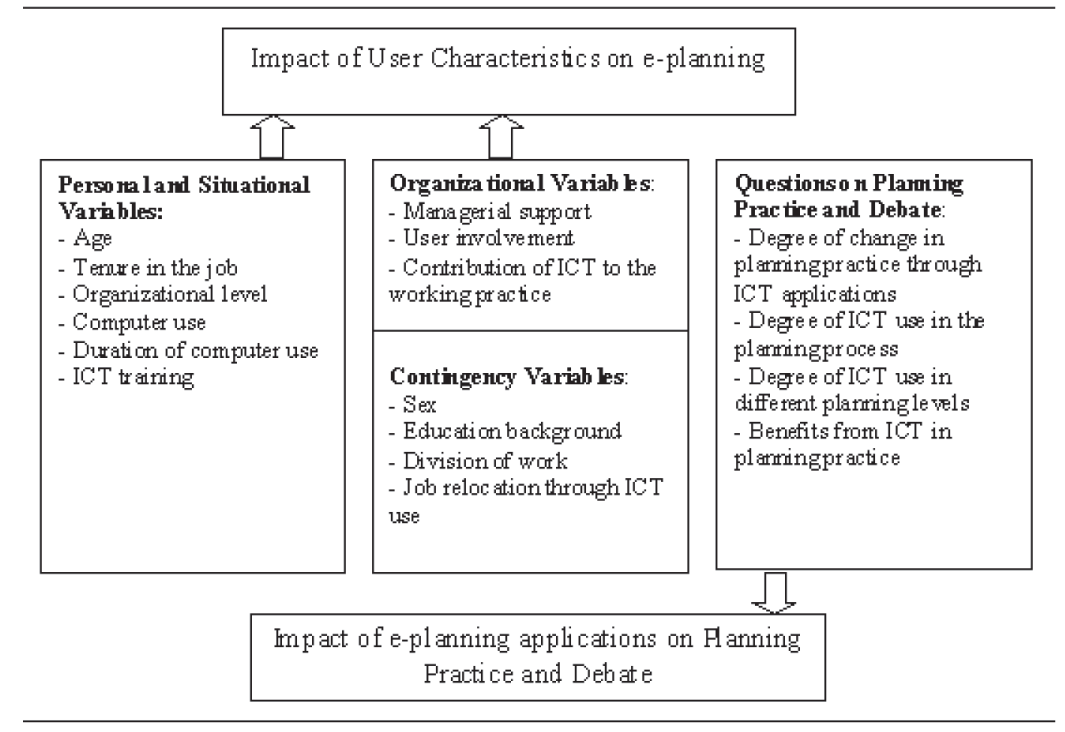

A user survey was conducted in the planning departments of selected Metropolitan Municipalities - Ankara, Izmir, Bursa - in 2004 (Velibeyoglu, 2004). The user survey was applied to all staff members in the planning departments $(n=47)$. The participants were asked to fill out all the 17 structured questions within three major parts even if they were not familiar with the e-planning applications. This survey had three major aims: (1) to draw a profile of planning practitioners working in the respondent municipal organizations (e.g. age, sex, education, computer literacy, job title, duration of work), (2) to measure the degree of their knowledge of planning technologies and their perception of implementation of e-planning applications in the department, (3) to identify their attitude toward new technologies and their future role in planning practice and debate. Variables that were used in this survey are listed in Figure 1.

Additionally, interviews were conducted with managers in the case study organizations to learn more about implementation process. This step consisted of six structured qualitative interviews and ten complementary interviews with other responsible interviewees in and out of respondent organizations. The interviewees were selected based on their influence on the development of e-planning applications in the department and professional reputation -preferably the chief executive of the department. All interviews were carried out at the interviewee's place of work. To verify and supplement the interview, other complementary data was also used.

\section{User Characteristics}

Personal and situational characteristics may influence one's perception of information and the way one processes such information. Individuals with distinct characteristics and backgrounds are expected to have unique ways of interacting with information systems and, consequently, have different attitudes and behavior toward such systems (Khalil \& Elkordy 2001). In this context, the first part of the survey investigated the relationship of user's age, sex, education background, division of work, tenure in the job, organizational level, ICT training and duration of computer use (Tables 1 and 2). 
Table 1. Frequency distribution of personal and situational variables

\begin{tabular}{|c|c|c|}
\hline & Frequencies & Percent \\
\hline \multicolumn{3}{|l|}{ Age: } \\
\hline (1) $20-25$ & 2 & 4.3 \\
\hline (2) $26-31$ & 15 & 31.9 \\
\hline (3) $32-37$ & 17 & 36.2 \\
\hline (4) $38-43$ & 9 & 19.1 \\
\hline (5) $44-49$ & 3 & 6.4 \\
\hline (6) $50+$ & 1 & 2.1 \\
\hline \multicolumn{3}{|l|}{ Sex: } \\
\hline Female & 31 & 66 \\
\hline Male & 16 & 34 \\
\hline \multicolumn{3}{|l|}{ Education background: } \\
\hline Undergraduate Degree & 40 & 85.1 \\
\hline Master Degree & 7 & 14.9 \\
\hline \multicolumn{3}{|l|}{ Tenure in the job: } \\
\hline (1) Less than one year & 1 & 2.1 \\
\hline (2) $1-2$ years & 2 & 4.3 \\
\hline (3) $3-5$ years & 5 & 10.6 \\
\hline (4) $6-10$ years & 18 & 38.3 \\
\hline (5) $11-15$ years & 14 & 29.8 \\
\hline (6) 16 years or more & 7 & 14.9 \\
\hline \multicolumn{3}{|l|}{ Organizational Level: } \\
\hline (1) City planner and Other Staff & $37(+7)$ & 93.6 \\
\hline (2) Department manager & 2 & 4.3 \\
\hline (3) Division Manager & 1 & 2.1 \\
\hline \multicolumn{3}{|l|}{ Computer Training: } \\
\hline (1) Formal Computer Training & 26 & 55.3 \\
\hline $\begin{array}{l}\text { (2) Informal or no computer } \\
\text { training }\end{array}$ & 21 & 44.7 \\
\hline
\end{tabular}

\section{Correlation Analysis}

In this part of the study, the selected variables of personal and situational characteristics are compared to the uses of e-planning applications expressed by the staff in respondent organizations. All possible e-planning applications were grouped according to Piracha and Kammeier's (2002) classification of planners' knowledge namely, "hands-on use" and "advanced level use":

- Hands-on use includes basic CAD, basic GIS, Office Programs and Internet-based tools.

- Advanced level use requires some additional knowledge including Planning Support Systems (PSS), MIS and Project Management tools (PM), Statistical and Modeling programs, and knowledge of computer programming (Table 3). The results of correlation analysis have been obtained as follows:

Age: A person's willingness to accept a new technology or a change may differ with the person's age. Since younger users generally display a more positive attitude toward the information system, they are more ready to accept the change. Anegative correlation between hands-on software use and age $(\mathrm{r}=-0.39, \mathrm{p}<0.01)$ has been found.

Tenure in the Job: User attitude and behavior toward e-planning applications are expected to vary with the user's work experience, measured as tenure in the industry, organization, or job. A

Table 2. Mean rankings of users

\begin{tabular}{|l|l|l|}
\hline & \multicolumn{1}{|c|}{ Mean (years) } & \multicolumn{1}{c|}{ S.D. } \\
\hline Age & $2.98(32-37)$ & 1.07 \\
\hline Tenure in the job & $4.34(6-10)$ & 1.12 \\
\hline Duration of computer use & 5.11 & 2.88 \\
\hline
\end{tabular}


Table 3. Frequency distribution of planners' knowledge of e-planning applications $(n=47)$

\begin{tabular}{|c|c|c|c|c|c|c|c|c|}
\hline \multirow[b]{3}{*}{ Hands-on Software } & \multicolumn{6}{|c|}{ Knowledge on E-Planning Applications } & \multirow{3}{*}{ Mean } & \multirow{3}{*}{ S.D. } \\
\hline & \multicolumn{2}{|c|}{ Don't know (1) } & \multicolumn{2}{|c|}{$\begin{array}{l}\text { Heard of/read } \\
\text { about (2) }\end{array}$} & \multicolumn{2}{|c|}{ Worked with (3) } & & \\
\hline & Freq. & $\%$ & Freq. & $\%$ & Freq. & $\%$ & & \\
\hline CAD & 5 & 10.6 & 13 & 27.7 & 29 & 61.7 & 2.51 & .69 \\
\hline GIS & 9 & 19.1 & 23 & 48.9 & 15 & 31.9 & 2.13 & .71 \\
\hline Office & 1 & 2.1 & 8 & 17 & 38 & 80.9 & 2.79 & .46 \\
\hline Internet & 2 & 4.3 & 6 & 12.8 & 39 & 83 & 2.79 & .50 \\
\hline \multicolumn{9}{|c|}{ Advance Level Software Applications } \\
\hline Programming Tools & 24 & 51.1 & 21 & 44.7 & 2 & 4.3 & 1.53 & .58 \\
\hline PSS & 40 & 85.1 & 7 & 14.9 & 0 & 0 & 1.15 & .36 \\
\hline MIS/ PM & 32 & 68.1 & 15 & 31.9 & 0 & 0 & 1.32 & .47 \\
\hline Spreadsheet & 28 & 59.6 & 16 & 34 & 3 & 6.4 & 1.47 & .62 \\
\hline
\end{tabular}

negative correlation also found between 'handson software use' and 'tenure in the job' $(\mathrm{r}=-0.53$, $\mathrm{p}<0.01$ ) on sampling data.

Organizational Level: The organizational level of the user's job determines his/her responsibilities and decisions and, consequently, his/her informational needs. Therefore, computer use may vary at different managerial levels. A negative correlation found between hands-on software use and organizational level $(\mathrm{r}=-0.33, \mathrm{p}<0.05)$. This indicates that people at the managerial positions do not need to improve their knowledge in terms of hands-on software use. Besides, findings also support the results in the "tenure in the job" category. However, since the proportion of the people at managerial position is low $(6.4 \%)$ and the study does not focus directly on the use of ICT by managers, it may be difficult to reach a generalization from these findings.

Computer use: Of the people working in the planning departments surveyed, $72 \%$ of them (37/47) use computers on their daily work practice. All the ones who do not use computers do not use any type of ICT software either.

Duration of Computer use: Lengthy use of eplanning applications may strengthen the user's belief in its usefulness, which, consequently, may increase his/her use of the system. In this survey, the positive correlation between hands-on software use and duration of computer use $(\mathrm{r}=0.41$, $\mathrm{p}<0.01)$ supports this statement. Lengthy use of e-planning applications by planning practitioners (mean $=5.11$ years) has had a positive impact on hands-on software use.

Computer Training: It was found that there was no significant correlation between computer training and hands-on software use. It was also found that although $55.3 \%$ of the people (26/47) have received formal computer training, they do not use e-planning applications related to their everyday tasks at work; in practice, it may be one of the likely explanations for this inconsistency. Another explanation is that even though $44.7 \%$ of the people (21/47) have not received formal computer training, they may be able to use software packages in practice with the help of the knowledge gained during informal processes.

\section{Other Findings}

- Education background, gender, and division of work were found to have no effect on users' attitudes toward hands-on software use. 
- No correlation has been encountered between software requiring advance level knowledge (e.g., planning support systems, electronic spreadsheet, or hypermedia tools) and personal and situational variables. Advance level software applications have not yet been utilized in the respondent organizations since the planning practitioners' knowledge that has related to them is very limited. There is a positive correlation encountered, although small, between "software requiring advance knowledge" and "duration of computer use" in terms of programming $(\mathrm{r}=0.35, \mathrm{p}<0.05)$ and electronic spreadsheet $(r=0.29, p<00.5)$ software. On the other hand, the ratio of handson software use is relatively high (63.8\%) within the respondent organizations that provide an opportunity in terms of awareness rising for advance level e-planning applications.

- Another set of variables affecting the usage of e-planning applications are organizational variables namely "user involvement" and "management support". User involvement is defined as a psychological state, which refers to the importance and personal relevance of a system to its users. Management support is defined as the extent to which the upper managerial levels provide an appropriate amount of support for information technologies and systems (Seliem et al., 2003). It is expected that both user involvement and management support lead to an increase in the system usage. When scrutinizing hands-on software usage there was no significant relationship found in terms of management support and user involvement. However, management support seems to have positive influence on user involvement $(\mathrm{r}=0.35, \mathrm{p}<0.05)$. More than half of the respondents (31/47) say that they are encouraged to use e-planning applications within their organizations.
The majority of the respondents $(89.4 \%)$ also need to use e-planning applications in their daily planning tasks. While the ratio of computer use is $72.4 \%$ and handson software use $63.8 \%$, the need to use e-planning applications is far above these numbers. This situation confirms respondents' positive attitude towards e-planning applications without being influenced by the organizational environment. As a matter of fact, $93.7 \%$ of the respondents found e-planning applications useful in their daily work. Another result obtained, in terms of organizational determinants, is that the respondents' ability to use e-planning applications has no positive impact on their organizational levels. Although the managers claims that capability to use ICT-based software was one of the most important criteria to be considered during the recruitment process, as survey results suggest, using e-planning applications does not play an important role in personal carrier development at work.

\section{Regression Analysis}

Following the results of correlation analysis, the total numbers of independent variables were condensed into four personal-situational dimensions and two organizational dimensions respectively. A stepwise regression analysis was performed on the data set. The objective was to use the several

Figure 2. Relations of independent variables and dependent variable

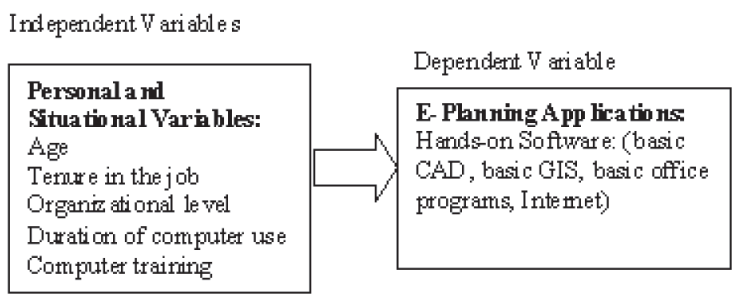


independent variables whose values were known to predict the single dependent value. This technique was repeated until it was determined that all significant predictor variables had been included (Figure 2). The given three models have predicted the independent variable (Hands-on Software use) in various degrees (Table 4).

\section{Planners' Perception of E-Planning Applications}

The second part of the survey is devoted to planning practitioners' perception of new technologies on urban planning practice and debate. The findings of this part can be summarized as follows:

Firstly, respondents were asked whether widespread use of e-planning applications make significant changes in urban planning practice or not. The majority of the planners (38/47) who have answered this question think that using e-planning applications will have significant transformational effects on the nature of urban planning practice. This underlines the fact that technological developments have a stronger impact on the respondents than the view of "new tools to perform old tasks" (see Klosterman, 2001).

Secondly, respondents were asked to rank the frequency of using e-planning applications during urban planning process from "the most" to "the least" on a 5-point Likert scale. Findings suggested that data collecting, issuing and evaluating features of e-planning applications were pointed as the most important (mean=1.58) whereas in- fluence of these applications as an enabler on the participation process in planning was evaluated as the least important (mean=4.17). E-planning applications were not considered as a new participation means by the respondents. This result also confirms the common idea that new technologies support the techno-rational side of planning (see Wheeler, 2001).

Thirdly, respondents were asked to rank 'at which level of the planning process were eplanning applications used most effectively' on a 4-point Likert scale from the "the most" to "the least". These applications were said to be used the most frequently at the 'urban design' and 'community planning' levels. Considering that the majority of software packages used in urban planning practice is CAD-based and mostly effective on architectural scale, one may find the results reasonable. Findings alternatively indicate the need for the establishment of an urban information system that would be appropriate at planning levels such as regional or metropolitan planning.

Lastly, respondents were asked to rank the benefits of using e-planning applications during urban planning process from "the most" to "the least" on a 5-point Likert scale. They gave more importance to data collection and processing (mean=1.36), considering that these applications can also substitute routine planning tasks (mean=2.38). Here, too, functions such as decision-support, participation and data-sharing capability of e-planning applications seemed to have been neglected by respondents. It would be

Table 4. Stepwise regression: ( $n=47)$ ((1) Dependent Variable: hands-on software use)

\begin{tabular}{|c|c|c|c|c|c|}
\hline Model & R & R Square & Adj. R Square & $\begin{array}{c}\text { Std. Error of the } \\
\text { Estimate }\end{array}$ & F \\
\hline 1 & $.442^{\mathrm{a}}$ & .196 & 173 & .380 & 8.51 \\
\hline 2 & $.608^{\mathrm{b}}$ & .370 & .332 & .341 & 9.96 \\
\hline 3 & $.675^{\mathrm{c}}$ & .456 & .407 & .321 & 9.22 \\
\hline
\end{tabular}

a. Predictors: tenure in the job

b. Predictors: tenure in the job, duration of computer use

c. Predictors: tenure in the job, duration of computer use, computer training 
possible to have improvements in these areas if a complete urban information system with all its functions working efficiently was established and if the participants' knowledge and skills to use the software was substantially improved.

\section{Obstacles and Benefits about Implementation Process}

Interviews with managerial staff in respondent organizations indicated some obstacles and benefits derived from e-planning applications. It is obvious that despite increasing use of e-planning applications in planning departments, it will take some time to realize the benefits of their implementation. In fact, even though the planning departments of respondent municipal organizations may have more advantages in particular areas compared to the other small scale municipalities, these selected organizations have a very short history of implementation. Therefore, while the obstacles were mentioned in detail by the interviewees, the benefits derived from implementation remained relatively peripheral for them. Besides, since the interviewees were planning heads or professional staff members, views of elected officials, other decision-making bodies, and citizens on obstacles and benefits from e-planning applications were reflected only indirectly.

In order to form a systematic framework to summarize implementation hurdles, a 'pentagon prism model' was adopted (see Vonk 2003):

\section{Software-Hardware}

- $\quad$ Software and hardware systems are not adjusted to perform daily planning tasks and they are incompatible with current planning rules and legislations.

\section{Humanware}

- Personnel who do not follow up technological innovations (quality);
- Shortage of staff which is open to ICTbased work processes (quantity).

\section{Dataware}

- Insufficient and unreliable supply of base maps, cadastre maps and other spatial data that would be essential for urban planning functions;

- Problem of updating digital data periodically;

- Insufficient planning information shared with the public that reduces the opportunity of participatory practices;

- Digital data repetitions due to miscommunication between organizations.

\section{Orgware}

- Existing ICT technologies which do not match the idea of e-local government;

- Canceling investments on e-planning applications as a result of constant changes in the managerial levels;

- Authorities approve technical reports not having full comprehension of them and give limited support for their implementation.

\section{Planning Task \& Work Process}

- There is an urgent need to form teams that would work on contemporary planning of good quality rather than on the quantity of plan making;

- Although e-planning applications have been established, most of the analysis essential for urban planning is still done through traditional methods and in a twodimensional environment;

- $\quad$ Production of digital data (both spatial and attribute data) has not been fully adjusted to the needs of urban planning tasks;

- $\quad$ There is considerable waste of time during auditing and approval processes as a result 
of not having office automation and digital archive that consists of information such as planning decisions and planning approval dates.

External World (e.g., Legal Rules, Finance, Politics)

- Digitally-produced plans have not legal validity;

- It is not possible to encourage the personnel to use e-planning applications within the existing legislation;

- Establishing legal procedures related to selling, sharing and copywriting of plans created in a digital environment is still lacking in terms of organizational bodies that would deal with such problems.

Possible benefits derived from implementation of e-planning applications can be summarized in two main categories. Increase in the possible benefits derived from implementation depends on the elements such as diversification in areas of use, reorganization of work process and increase in duration of utilization.

\section{Improvement in Decision-Making}

- Accuracy in technical information collected through e-planning applications encourages decision-makers towards technorational accuracy;

- Carrying planning tasks into a digital environment provides an opportunity for planning departments to communicate with other departmental units and politicians more easily and to convey the problems to them more quickly and accurately;

- During quantitative plan audits the risk of wasting time gets smaller and the process of decision making and implementation gets easier.

\section{Improvement in Work Process}

- There is efficient use of time through use of planning software that is in compliance with plan making procedure and consequently the efficiency in daily routine tasks,

- There is considerable reduction in errors during routine planning tasks and hence improvement in planning accuracy;

- It is possible to facilitate control among different planning scales, and there is an opportunity for design and presentation at any required scale;

- $\quad$ Analysis and synthesis in planning studies are faster and accurate since various data layers may be superimposed easily in a computerized environment.

\section{FUTURE RESEARCH DIRECTIONS}

Studies of Obermeyer and Pinto (2008) bring forth a body of literature that draws attention to the different kinds of ICT research. To them, ICT research would follow a pattern that begins with technological problems, proceeds through financial aspects, continues with institutional issues, and finally culminates in examinations of the effect of the technology on society. In the future, ICT research in developing countries should give priority to social and organizational dimensions contrary to what happened until now, as the case of Turkey seems to suggest.

It is also necessary to undertake future studies on the measurement of tangible and intangible benefits of e-planning projects. Cost-benefit analysis on tangible benefits can be used as an effective tool. Intangible benefits (e.g. better working morale, better communication within the organization, responsibility, organizational effectiveness) bear great importance in the implementation of information systems (see Pick, 2005). Strategic tools such as 'stakeholders analysis' and 'SWOT 
analysis' could provide important clues for institutions to be aware of their own characteristics and to be able to design strategies to overcome implementation problems.

\section{CONCLUSION}

This chapter revealed a high level of awareness about e-planning applications among planning practitioners. The major findings of this study confirm that the organizational factors are important obstacles to the improvement of e-planning applications in urban planning agencies. Especially the organizational aspects of higher order information systems, like GIS, are among the most important barriers in the implementation process. The key points identified in the user survey and interviews in the case study organizations can be summed up as follows:

- Potential benefits expected from e-planning applications are closely related with the elements such as the diversification of the areas of use, re-organization of the work process, and the extension of the implementation period.

- In the case study organizations, it has been seen that the most important obstacles that could affect the functioning of planning technologies are orgware and dataware. One of the interesting results is that humanware does not constitute an important obstacle for implementation. In the interviews, staff quality was defined by the head of planning departments as one of the most important strengths of the institution. The fact that the mean age of the planners in these institutions is relatively low (mean $=2.98$ equivalent of 32-37) and that duration of computer use is high (mean $=5.11$ years), and users involvement is quite high ( $90 \%$ of total respondents) is effective.
- Another important point is environmental instability and change. It is also known that the effect of external macro factors is highly important during the process of implementation especially in developing countries.

Like many things in the knowledge era, it seems inevitable that there must be some changes in the role of planners. The results of the research indicate that the planners working in respondent municipal organizations are young (70\% age between $26-37)$, have high job tenures (6-10 years) and more than half have taken formal computer training $(55.3 \%)$. More than half $(78 \%)$ of the practitioners have experience of 5 years in computer use. The three variables namely "tenure on the job", "duration of computer use", and "computer training" were able to account for approximately $40 \%$ of the total causes of hands on software usage.

In conclusion, e-planning technologies are not value-neutral and these tools have the possibility to shape the goals and the agenda of the profession (Wheeler, 2001). In the case study organizations, an important part of urban planners think that applying e-planning technologies would have an important role in the future planning practice. Even e-planning technologies have not replaced most of the routine planning tasks, and a great majority of respondents found these technologies to be an important contribution to their work practice. Since planners' jobs mostly cover other than non-routine tasks, unlike clerical staff, they are feared about their job satisfaction in a lesser extent. Although using e-planning applications does not constitute justification for job ranks within the organization being equipped with high level of computer competency gave ample opportunity for autonomy, variety and feedback in work experience, and also provides collaborations with other non-planner professionals such as computer experts. Eventually, this study illustrates that, in spite of the optimism, a considerable amount of time is still needed for Turkish public planning 
agencies in their quest for computer-aided planning to be fully tailored into daily work practice.

\section{REFERENCES}

Budthimedhee, K., Li, J., \& George, V. (2002). ePlanning: A Snapshot of the Literature on Using the World Wide Web in Urban Planning. Journal of Planning Literature, 17(2), 227-246. doi:10.1177/088541202762475964

Cavric, B. (2002). Human and Organisational Aspects of GIS Development in Botswana. Paper Presented at GSDI 6 Conference, Budapest, Romania.

DIE. (2000). Devlet Istatistik Enstitusu [Turkish Statistical Institute]. Ankara, Turkey: Nufus Sayimi Sonuclari. [Results of the 2000 General Population Census]

Khalil, O. E. M., \& Elkordy, M. M. (2001). The Relationship of Some Personal and Situational Factors to IS Effectiveness: Empirical Evidence from Egypt. In Shaw, N. G. (Ed.), Strategies for Managing Computer Software Upgrades. London: Idea Group Inc.

Klosterman, R. E. (2001). Planning Support Systems: A new perspective on Computer-aided Planning. In Brail, R., \& Klosterman, R. (Eds.), Planning Support Systems. New York: ESRI, Inc.

Nedovic-Budic, Z. (2008). Afterword: Planning for Creative Urban Regions. In Yigitcanlar, T., Velibeyoglu, K., \& Baum, S. (Eds.), Creative urban regions: harnessing urban technologies to support knowledge city initiatives (pp. 312-318). Hershey, PA: IGI Global.

Obermeyer, N. J., \& Pinto, J. K. (2008). Managing Geographic Information Systems (2nd ed.). New York: The Guilford Press.
Pick, J. (2005). Costs and benefits of GIS in Business. In Pick, J. (Ed.), Geographic Information Systems in Business. Hershey, PA: IGI Publishing. Piracha, A. L., \& Kammeier, D. H. (2002). Planning-support systems using an innovative blend of computer tools. IDPR, 24(2), 203-221.

Seliem, A., Ashour, A., Khalil, O., \& Millar, S. (2003). The Relationship of Some Organizational Factors to Information Systems Effectiveness: A Contingency Analysis of Egyptian Data. Journal of Global Information Management, 11(1).

Velibeyoglu, K. (2004). Institutional Use ofInformation Technologies in City Planning Agencies: Implications from Turkish Metropolitan Municipalities. Unpublished doctoral dissertation, Izmir Institute of Technology, Izmir, Turkey.

Velibeyoglu, K. (2005). Urban Information Systems in Turkish Local Governments. In Marshall, S., Taylor, W., \& Yu, X. (Eds.), Encyclopedia of developing regional communities with information and communication technology (pp. 709-714). Hershey, PA: Information Science Reference.

Velibeyoglu, K., \& Saygin, O. (2005). Spatial Information systems in Turkish Local Government: implications from recent practices. Paper presented at the CUPUM 05: Ninth International Conference on Computers in Urban Planning and Urban Management, CASA, London.

Velibeyoglu, K., \& Yigitcanlar, T. (2008). Understanding the supply side: ICT experience of Marmara, Turkey. In Yigitcanlar, T., Velibeyoglu, K., \& Baum, S. (Eds.), Creative Urban Regions: Harnessing Urban Technologies to Support Knowledge City Initiatives (pp. 245-262). Hershey, PA: Information Science Reference.

Vonk, G. (2003). Opportunities for Participatory Planning Support Systems (PPSS) in spatial planning. UNetworks in the Delta: Projects $U$. The Netherlands: Utrecht University. 
Wheeler, S. (2001). Technology and Planning: A Note of Caution. Berkeley Planning Journal, $15,85-89$.

Wolcott, P., \& Çagiltay, K. (2001). Telecommunications, Liberalization, and the Growth of the Internet in Turkey. The Information Society, 17,133-141.doi:10.1080/019722401750175685

\section{ADDITIONAL READING}

Cackowski, J. M. (2002). Commentary on Information Technology and Planning. Journal of Planning Literature, 17(2), 187-188. doi:10.1177/088541202762475937

Campbell, B. R., \& McGrath, G. M. (2003). The Information System Within the Organization: A Case Study. In Cano, J. (Ed.), Critical Reflections on Information Systems: A Systematic ApproachU. Hershey, PA: Idea Group Inc.

Carr, T. R. (2003). Geographic Information Systems in the Public Sector. In Garson, G. D. (Ed.), UPublic Information Technology: Policy and Management Issues. UHershey. PA: Idea Group Inc.

Geertman, S. (2002). Participatory planning and GIS: a PSS to bridge the gap. Environment and Planning. B, Planning \& Design, 29, 21-35. doi:10.1068/b2760

Gilfoyle, I., \& Thorpe, P. (2004). Geographic Information Management in Local Government. Boca Raton, FL: CRC Press. doi:10.1201/9780203484920

Hee, C., \& Bae, C. (2002). Information technology for planners: the gmforum. Environment and Planning. B, Planning \& Design, 29, 883-894. doi:10.1068/b12823t
Heeks, R. (1999). Reinventing government in the information age: international practice in IT-enabled public sector reform (Heeks, R., Ed.). London: Routledge. doi:10.4324/9780203204962

Heeks, R. (2002). Information Systems and Developing Countries: Failure, Success, and Local Improvisations. The Information Society, 18, 101-112. doi:10.1080/01972240290075039

Mennecke, B. E., \& West, L. (2001). Geographic Information Systems in Developing Countries: Issues in Data Collection, Implementation and Management. Journal of Global Information Management, 9(4), 44-54.

Nedovic-Budic, Z. (2002). Local Government Applications. In Bossler, J. (Ed.), Manual of Geospatial Science and Technology (pp. 563-574). London: Taylor and Francis.

Nedovic-Budic, Z., \& Pinto, J. K. (2001). Organizational (Soft) GIS Interoperability: Lessons From the U.S. International Journal of Applied Earth Observation and Geoinformation, 3(3), 290-298. doi:10.1016/S0303-2434(01)85035-2

Pitkin, B. (2001). A Historical Perspective of Technology and Planning. Berkeley Planning Journal, 15, 32-55.

Ramasubramanian, L. (1999). GIS Implementation in Developing Countries: Learning from Organisational Theory and Reflective Practice. Transactions in GIS, 3(4), 359-380. doi:10.1111/1467-9671.00028

Sims, I. M., \& Standing, C. (2003). Impact on Society: The Missing Dimension in Evaluating the Benefits of IT in the Public Sector. In Kamel, S. (Ed.), UManaging Globally with Information Technology. London: IRM Press.

Tecim, V. (2001). Cografi Bilgi Sistemleri Tabanli ValilikBilisim Sistemi [A GIS based Governorship Information System]. Istanbul: Paper Presented at Cografi Bilgi Sistemleri Bilisim Günleri / GIS Days in Turkey, Fatih University. 
Vonk, G. A., Geertman, S., \& Schot, P. (2006). New Technologies Stuck in Old Hierarchies: The Diffusion of Geo-Information Technologies in Dutch Public Organizations. Public Administration Review, 67(4), 745-756. doi:10.1111/j.15406210.2007.00757.x

\section{KEY TERMS AND DEFINITIONS}

Local e-Government: Refers to information, services or transactions that local governments provide online to citizens using Internet and Web sites.

Planning Support System (PSS): Is an integrative system in urban planning consisting of a combination of geographic information system, a broad range of computer-based models and a variety of visualization tools for presenting the results of the models.

Pentagon-Prism Model: An assessmentmethodology in order to identify critical success factors in urban policy. It includes a systematic investigation into five necessary conditions: hardware (the tangible investments), software (the investment in knowledge), orgware (the organizational struc- ture), finware (the financial aspects) and ecoware (the effects on the ecology).

Spatial Data: Any information about the location and shape of, and relationships among, geographic features, usually stored as coordinates and topology.

Spatial Decision Support System (SDSS): Is a spatial information system supporting decision making process related to complex spatial problems such as determining the optimal location of public services such as educational institutions or public parks.

SWOT Analysis: Is a scan of the internal and external environment as an important part of the strategic planning process. Environmental factors internal to the organization usually can be categorized as strengths (S) or weaknesses (W), and those external to the organization can be classified as opportunities $(\mathrm{O})$ or threats $(\mathrm{T})$.

Urban Information System (UIS): Is a powerful means for governments in meeting long-term strategic planning and management challenges. It provides a heightened awareness of the interdependency among environmental, social, and economic health and the impact of decisions made by neighboring jurisdictions, government agencies, and private business. 